\title{
Cálculo Biliar "Perdido": Um Novo Problema para o Ginecologista na Abordagem do Abdome Agudo ?
}

\author{
"Lost" Gallstone: A New Problem for the Gynecologist in Acute Abdomen Management ? \\ José Carlos Menegoci, Edson Alcoléa Filho, Álvaro Augusto Germano Gutierres
}

\section{SUMÁRI0}

Os autores relatam o caso de uma paciente com 35 anos de idade, submetida à colecistectomia videolaparoscópica há 1 ano e que apresentou quadro sugestivo de salpingite aguda com abscesso. Durante a laparotomia notou-se um abscesso que era limitado anteriormente pelo peritônio parietal e músculo reto anterior direito do abdome, e posteriormente pelo corno uterino e pelo ligamento redondo à direita. Neste abscesso havia estrutura a seguir identificada como cálculo biliar. São discutidos os aspectos relacionados à patogenia, tratamento e prevenção desta complicação que vem sendo relatada com freqüência em virtude do maior uso da cirurgia laparoscópica.

PALAVRAS-CHAVE: Abdome agudo. Doença inflamatória pélvica.

\section{Introdução}

O uso mais freqüente da cirurgia laparoscópica tem levado ao aparecimento de algumas complicações que eram incomuns ou inexistentes quando o método era utilizado apenas com o objetivo de diagnóstico. Algumas destas complicações poderão se tornar cada vez mais freqüentes, sendo seu conhecimento necessário para o diagnóstico diferencial com moléstias já conhecidas, o que permitirá diagnóstico e tratamento precoces, proporcionando redução da morbidade e da eventual mortalidade. Relatamos no presente artigo o caso de uma paciente cujo diagnóstico inicial foi de moléstia inflamatória pélvica com abscesso e na qual se constatou um abscesso ocasionado por cálculo biliar perdido em uma colecistectomia laparoscópica.

\section{Relato do Caso}

Paciente P.A.G.M., 35 anos, sexo feminino, nos procurou com queixa de dor em fossa iliaca

Faculdade de Ciências Médicas do Centro de Ciências Médicas e Biológicas de Sorocaba (PUC-SP); Disciplina de Ginecologia e II Clinica Cirúrgica

Correspondência:

José Carlos Menegoci

Rua do Zico, 131 - Jardim Santa Rosália

18095-000 - Sorocaba - SP direita e hipogástrio, de moderada intensidade, com aumento progressivo há 2 dias, quando passou a se acompanhar de febre (cerca de $38^{\circ} \mathrm{C}$ ). Referia colecistectomia videolaparoscópica há 1 ano. Ao exame, a paciente se encontrava febril $\left(37,9^{\circ} \mathrm{C}\right)$, o abdome era flácido e não exibia sinais de irritação peritoneal. Notava-se a presença de massa em região da fossa ilíaca direita e hipogástrio, de consistência firme, discretamente dolorosa, com cerca de $10 \mathrm{~cm}$ de diâmetro. O toque bimanual revelou massa para-uterina direita, dolorosa, arredondada e com consistência firme, com pouca mobilidade e em aparente continuidade com o corpo uterino. O hemograma estava dentro das características normais, sem desvio à esquerda e a velocidade de hemossedimentação foi de $68 \mathrm{~mm}$ e de $109 \mathrm{~mm}$, na primeira e segunda horas, respectivamente. O exame ultra-sonográfico revelou útero e anexo esquerdo de aparência normal e a presença de massa heterogênea parauterina direita com áreas císticas e regiões de maior refringência no seu interior. Foi indicada laparotomia pela suspeita de abscesso dos anexos à direita.

Durante a laparotomia notou-se que o útero estava aderido à parede anterior do abdome, assim como o ligamento redondo direito. Ao se descolar estas estruturas da parede abdominal, ao nivel da prega vésico-uterina, houve escoamento de coleção purulenta. Acompanhando-se o trajeto pelo qual se dava o escoamento, distinguiu-se abscesso 
que também envolvia as fibras do músculo reto anterior direito. Explorando o interior da cavidade foram identificadas formações sólidas com aspecto de cálculo biliar (Figura 1). Estas formações foram removidas, promovendo-se a limpeza da área. A seguir o abscesso foi drenado, mantendo-se antibioticoterapia pelo período de 10 dias. No dia seguinte, ao tomar conhecimento da natureza de seu problema a paciente informou que havia eliminado cálculos 6 meses após a cirurgia, por uma das incisões usadas durante a colecistectomia videolaparoscópica. A evolução pósoperatória se deu sem intercorrências, com alta hospitalar no quarto dia.

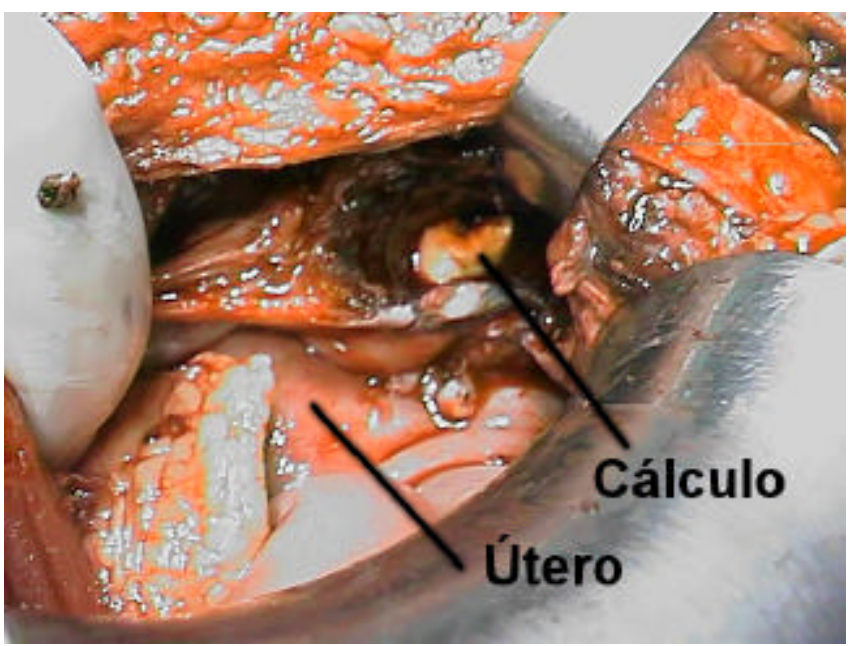

Figura 1 - Aspecto da pelve durante a laparotomia e localização de um cálculo.

\section{Discussão}

A colecistectomia realizada por videolaparoscopia (CVL) tem sido um procedimento praticado mundialmente, desde sua introdução por Mouret em 1987 e, na última década, passou a ser a primeira opção para o tratamento cirúrgico da litíase biliar. Seus índices de morbidade e mortalidade são comparáveis aos observados na colecistectomia aberta. Algumas complicações, quando se usa a via laparoscópica, parecem ser mais freqüentes como, por exemplo, as lesões da via biliar principal e a perfuração da vesícula biliar ${ }^{1}$. Nestas circunstâncias pode ocorrer derrame de cálculos, os quais podem não ser recuperados pelo cirurgião. As conseqüências da presença de cálculos biliares intraperitoneais eram conhecidas, porém incomuns até o advento da CVL para tratamento da litíase biliar ${ }^{2}$. Ultimamente têm sido relatadas complicações relacionadas ao "cálculo perdido", como empiema pleural, abscesso subfrênico e peritoniais, assim como a colelitoptise ${ }^{3,4,5,6}$.

A perda de cálculos se torna um grande problema, pois mesmo uma busca exaustiva pode não ter sucesso em remover todos eles. A evolução destes casos é variável e poucos relatos se referem ao problema. Deziel e Millikan ${ }^{1}$ relataram 77.604 casos de CVL, referindo derrame intraperitoneal de cálculos biliares em 35 pacientes dos quais apenas 3 desenvolveram abscessos. Jacob et al. ${ }^{2}$ referiram abscesso retroperitoneal como complicação tardia de cálculo vesical após perfuração da bexiga.

O problema existe porque o cálculo biliar é considerado um corpo estranho, podendo desencadear reação do tipo inflamatório. Somase a isto a freqüência com que ocorre a contaminação da bile e dos cálculos, que alcança até $30 \%$ em culturas de bile colhida durante a realização de colecistectomia ${ }^{7}$. A cultura do material contido em abscessos decorrentes de cálculos "perdidos" identificou microorganismos que comumente são encontrados na bile, como $E$. coli, Klebsiella pneumoniae e Enterococcus sp $p^{6}$.

Estudos experimentais demonstraram que os cálculos biliares determinam intensa reação inflamatória ${ }^{8,9}$. Quando bile foi adicionada aos cálculos introduzidos na cavidade peritoneal ocorreu supuração em 14\% dos casos, fato contestado por Welch et al. ${ }^{7}$, os quais referiram que cálculos intraperitoneais não determinaram supuração, mas apenas aderências mínimas em estudos experimentais. Recentemente foram relatados casos de abscessos que se desenvolveram no músculo psoas demonstrando a possibilidade de migração destes cálculos dentro do abdome ${ }^{5}$.

No caso que agora apresentamos a migração deve ter ocorrido, provavelmente pela goteira parietocólica, tendo o cálculo se abrigado na prega vésico-uterina, próximo à inserção do ligamento redondo direito, onde deve ter-se iniciado a reação inflamatória, seguida da formação de abscesso. Este caso demonstra a necessidade de se evitar a perda intraperitoneal de cálculos biliares, assim como a obrigatoriedade de se resgatar os cálculos "perdidos".

O tratamento definitivo destes abscessos deve incluir antibioticoterapia, drenagem e retirada completa dos cálculos, caso contrário poderá ocorrer recidiva ${ }^{6}$. Há relato da drenagem e retirada percutânea de cálculos. No entanto, em situações de dúvida quanto ao diagnóstico e em casos de localizações pouco favoráveis, deve-se recorrer à laparotomia exploradora.

Intercorrências como esta que relatamos não trazem descrédito à colecistectomia 
videolaparoscópica como método de tratamento da litíase biliar, embora já venham suscitando questionamentos legais ${ }^{10}$. No entanto, quando há referência deste procedimento nos antecedentes de pacientes que se apresentam com abdome agudo, o diagnóstico diferencial deve passar a incluir a possibilidade de abscesso decorrente de cálculos biliares perdidos.

\section{SUMMARY}

The authors report a case of a thirty-five-year-old patient, submitted to videolaparoscopic cholecystectomy one year ago, who appearently had acute salpingitis with abscess. During the laparotomy an abscess was observed, anteriorly limited by parietal peritoneum and the abdominal right anterior rectus muscle, and posteriorly by the horn of the uterus and by the right round ligament. In this abscess there was a structure later identified as gallstone. The aspects related to the pathogenesis, treatment and prevention, which have been reported frequently due to the increasing number of laparoscopic surgeries, are discussed.

KEY WORDS: Acute abdomen. "Lost" gallstone. Pelvic inflammatory disease.

\section{Referências}

1. Deziel DJ, Millikan KW. Complications of laparoscopic cholecistectomy: a national survey of 4292 hospitals and an analysis of 77604 cases. Am J Surg, 1993; 165:9-14.

2. Jacob H, Rubin KP, Cohen MC, Kahn IJ, Kan P. Gallstones in a retroperitoneal abscess: a late complication of perforation of the gallbladder. Dig Dis Sci 1979; 24:964-6.

3. Barnard, SP, Pallister I, Hendrick DJ, Walter N, Morritt GN. Cholelithoptypsis and empyema formation after laparoscopic cholecystectomy. Ann Thorac Surg 1995; 60:1100-2.

4. Freedman NA, Sigman HH. Incarcerated paraumbelical incisional hernia and abscess complications of a spilled gallstone. J Laparoendosc Surg 1995; 5:189-91.

5. Groebli Y, Hebert D, Tschantz P. The migrating spilled stone. Int Surg 1998; 83: 31-2.

6. Horton M, Florence MG. Unusual abscess patterns following dropped gallstones during laparoscopic cholecystectomy. Am J Surg 1998; 175:375-9.

7. Welch RJ, Hinder RA, Fitzgibbons RJ, Rouse JW. Gallstones in the peritoneal cavity. A clinical and experitmental study. Surg Laparosc Endosc $1991 ; 1: 246-7$.

8. Johnston S, O'malley K., Mcentee G, Grace P, Smyth $\mathrm{E}$, Bouchier-Hayer $\mathrm{D}$. The need to retrieve the dropped stone during laparoscopic cholecystectomy. Am J Surg 1994; 167:608-10.

9. Melo VA, Alves A, Gentil AC, Ferreira KO, Esmeraldo ACS, Alves KMB. Cálculo biliar na cavidade abdominal - estudo experimental em ratos. Rev Soc Bras Cir Laparosc 1997; 2:12-8.

10.Kern K. Malpractice litigation involving laparoscopic cholecystectomy. Arch Surg 1997; 132:392-8. 